\title{
Análise comparativa dos resultados do desempenho térmico da envoltória de uma edificação residencial pelos métodos de simulação do RTQ-R e da NBR 15575-1
}

\author{
Comparative analysis of the thermal performance of the \\ envelope of a residential building using the simulation \\ methods of RTQ-R and NBR 15575-1
}

\begin{abstract}
Arthur Santos Silva
Enedir Ghisi

Resumo

$\mathbf{E}$

ste trabalho tem por objetivo analisar comparativamente os resultados do desempenho térmico da envoltória de uma edificação residencial por meio dos métodos de simulação do RTQ-R e da NBR 15575-1. Para obter níveis de desempenho variados, foi realizado um experimento aleatório com amostragem pelo hipercubo latino. Selecionaram-se os parâmetros variáveis e geraram-se 500 combinações aleatórias. Foi considerado o clima de Florianópolis, SC, e utilizado o programa EnergyPlus para as simulações. Observou-se que, dependendo do cenário de análise, os métodos podem produzir resultados equivalentes ou não. A maior parte dos casos diferiu na análise do inverno, ou seja, 134 casos apresentaram nível A ou B no RTQ-R, e Mínimo ou Não atende pela NBR 15575-1. Para as análises de verão, há 66 casos em que o RTQ-R resulta em nível E, enquanto a NBR 15575-1 resulta em nível Intermediário. Apesar de a análise de sensibilidade indicar semelhança entre os métodos de simulação, o RTQ-R contempla um método de avaliação mais completo e abrangente. No entanto, mais atenção deve ser dada às próprias tabelas de classificação dos métodos, que podem ser as causas de algumas das discordâncias.

Palavras-chave: Simulação computacional. Desempenho térmico da envoltória. RTQR. NBR 15575-1. Análise de sensibilidade.

Abstract

This paper aims to compare the thermal performance results of the envelope of a residential building, using the RTQ-R and the NBR 15575-1 simulation methods. In order to obtain different levels of performance, a random experiment with the kLatin Hypercube Sampling method was performed. The variable parameters were selected and 500 random combinations were generated. The climate of Florianópolis-SC was considered, and the EnergyPlus computer programme was

Arthur Santos Silva Universidade Federal de Santa Catarina Florianópolis - SC - Brasil

Enedir Ghisi Universidade Federal de Santa Catarina Florianópolis - SC - Brasil

Recebido em 28/05/13 Aceito em 19/02/14 used. The results showed that, depending on the scenario analysed, the methods may give similar results. Most cases had different results over the winter, where 134 cases resulted in level A or B with RTQ-R, and Minimal or no-compliance with the NBR 15575-1. Over the summer, 66 cases resulted in level $E$ with $R T Q-R$ and Intermediate level with NBR 15575-1. Although the sensitivity analysis indicated similarity between the simulation methods, the $R T Q-R$ is a more complete and comprehensive evaluation method. However, more attention should be given to the methods' classification process, which may be the cause of some of the differences.

Keywords: Computer simulation. Thermal performance of the envelope. RTQ-R. NBR 15575-1. Sensitivity analysis.
\end{abstract}

SILVA, A. S.; GHISI, E. Análise comparativa dos resultados do desempenho térmico da envoltória de uma edificação 215 residencial pelos métodos de simulação do RTQ-R e da NBR 15575-1. Ambiente Construído, Porto Alegre, v. 14, n. 1, p. 213-230, jan./mar. 2014.

ISSN 1678-8621 Associação Nacional de Tecnologia do Ambiente Construído. 


\section{Introdução}

O consumo de eletricidade residencial representou 23,3\% do consumo total no Brasil em 2011 (EMPRESA..., 2012), sendo maior do que o setor comercial e menor do que o setor industrial. Por sua vez, a eletricidade representou $41,7 \%$ do consumo de energia primária no setor residencial.

$\mathrm{Na}$ tentativa de promover o uso racional de energia e eficiência energética de edificações, diversos programas foram criados por iniciativas governamentais para regulamentar a Lei $\mathrm{n}^{\circ} 10.295$, de 17 de outubro de 2001 (BRASIL, 2001a). Esta lei e o Decreto $\mathrm{n}^{\mathrm{o}} 4.059$, de 19 de dezembro de 2001 (BRASIL, 2001b), instituem o Comitê Gestor de Indicadores e Níveis de Eficiência Energética (CGIEE), para tratar dos assuntos de regulamentações, com planos, metas e fiscalizações.

Entre outros órgãos, a Agência Nacional de Energia Elétrica (Aneel), o Instituto Nacional de Metrologia, Normalização e Qualidade Industrial (Inmetro) e as Secretarias Executivas do Programa Nacional de Conservação de Energia Elétrica (Procel) serão responsáveis pelo apoio técnico ao CGIEE.

Segundo Kelly (2011), em um estudo de edificações residenciais na Inglaterra, os fatores determinantes para o consumo de energia são o número de ocupantes, a renda familiar, a área da edificação, as rotinas de uso e ocupação, o clima e sua classificação de eficiência energética.

Há necessidade em tornar as edificações mais eficientes por meio de regulamentações e normas. A certificação energética de edifícios está sendo realizada mundialmente, através de códigos e normas desenvolvidos por diversos países (CARLO; LAMBERTS, 2010).

Segundo Carlo e Lamberts (2010), há dois tipos de políticas na implementação da eficiência energética: limitações do nível de eficiência permitido por meio de índices mínimos de desempenho; e políticas que estabeleçam diferentes níveis para classificações por meio de uma certificação consolidada.

Nesse contexto, o termo "indicadores de desempenho" se faz necessário e é utilizado no contexto de métodos para a avaliação ambiental de edifícios para mostrar melhoria e também permitir comparação entre edificações (SILVA, 2007).

No escopo técnico das certificações, as ferramentas de simulação computacional ajudam a encontrar soluções de desempenho térmico, eficiência energética, otimização de sistemas, sendo uma boa prática no mercado de edificações (RAFTERY; KEANE; O’DONNELL, 2011).

A simulação tem o potencial de auxiliar no processo de projeto, analisando as edificações em termos de eficiência energética e possibilitando a comparação de inúmeras variáveis que influenciam no consumo de energia antes da construção (AUGENBROE, 2002). Isso ajuda a encontrar soluções otimizadas para as edificações em projeto e retrofit, da mesma forma que ajuda a entender as variáveis que mais influenciam no indicador que se quer analisar, abrindo a possibilidade para normalizações e índices mínimos de desempenho.

\section{Métodos de avaliação de desempenho de edificações}

Há normalizações que propõem métodos de avaliação da eficiência energética de edificações com o objetivo de padronizar configurações das simulações, fixar níveis de eficiência energética e fixar parâmetros exigíveis de propriedades térmicas.

No âmbito internacional, a Standard 90.1 (AMERICAN..., 2010) tem por objetivo propor requisitos mínimos de eficiência de edificações, exceto residências unifamiliares, para o projeto e construção, plano de uso e operação, e utilização de energias renováveis. A norma determina limites de área de aberturas, propriedades térmicas de componentes opacos e potências limites de iluminação, além de diversos requisitos para o sistema de condicionamento de ar.

O Brasil possui dois métodos para a avaliação do desempenho térmico de edificações residenciais por simulação computacional.

O primeiro método está no Regulamento Técnico da Qualidade para o Nível de Eficiência Energética de Edificações Residenciais (INSTITUTO..., 2012) ou RTQ-R. O mesmo foi elaborado tendo em vista a criação de um referencial brasileiro para promover eficiência energética nesse tipo de edificações, por meio de um consenso entre o Procel Edifica, da Eletrobrás, e o Programa Brasileiro de Etiquetagem (PBE), do Inmetro.

O segundo método está na norma de desempenho para edificações, a NBR 15575-1 (ABNT, 2013), que trata, além de outros temas, do desempenho térmico.

Os dois métodos propõem avaliações do desempenho térmico e/ou da eficiência energética, com diferentes parâmetros fixos, diferentes condições de contorno e diferentes indicadores de

216 Silva, A. S.; Ghisi, E. 
desempenho; ou seja, diferentes abordagens para a classificação do nível de desempenho.

Há poucos estudos que tratam de divulgar resultados de avaliação pelo RTQ-R ou pela NBR 15575-1. Nogueira et al. (2012) analisaram o impacto de diferentes estratégias bioclimáticas na classificação da eficiência energética da envoltória pelo método prescritivo do RTQ-R na cidade de Maceió, AL. Marin e Amorin (2012) avaliaram duas edificações de acordo com o RTQ-R pelo Método Prescritivo para a cidade de Antônio Prado, RS, sendo uma de arquitetura contemporânea e outra de arquitetura vernácula.

Lima, Pedrini e Alves (2012) avaliaram uma edificação da cidade Parnamirim, RN, representada pelo arquivo climático de Natal, $\mathrm{RN}$, e pela Zona Bioclimática 8 , pelo método de simulação do RTQ-R, além de simular casos adicionais para a verificação do impacto de parâmetros no desempenho térmico. Pouey, Brandalise e Silva (2012) compararam os resultados dos métodos prescritivo e simulação do RTQ-R em uma residência de Pelotas, RS. O nível de eficiência da envoltória obtido foi A e B, para o método de simulação e prescritivo respectivamente. Verificaram grande diferença no cálculo dos graus-hora de resfriamento, com níveis diferentes nos ambientes.

Alves, Pedrini e Lima (2012) propuseram uma edificação residencial multifamiliar que atenda prescrições de desempenho do RTQ-R. Ferreira e Pereira (2012) avaliaram o desempenho térmico de uma habitação para todas as Zonas Bioclimáticas do Brasil pelo método de simulação da NBR 15575-1. Brito et al. (2010) fizeram propostas para a alteração da NBR 15575-1. Os autores consideraram-na insatisfatória, tanto pela faixa de temperatura adotada na avaliação quanto pela simulação de apenas um dia típico. Loura, Assis e Bastos (2011) compararam os resultados do desempenho térmico da envoltória pelo método prescritivo do RTQ-R e pelo método simplificado da NBR 15575-1. O resultado do desempenho térmico para uma edificação multifamiliar e clima do Rio de Janeiro foi nível B pelo RTQ-R, mas não atendeu ao mínimo da NBR 15575-1 no verão. Foi verificada a divergência entre os métodos de avaliação, o que pode gerar inconsistência em sua aplicação no mercado da construção.

Não há nenhum estudo comparando especificamente os resultados do RTQ-R em relação aos resultados da NBR 15575-1, por meio de diversas condições da envoltória. Além disso, existe a necessidade de discutir a abordagem utilizada pelos dois métodos em relação à simulação computacional. Sendo assim, o objetivo do trabalho é comparar os resultados do desempenho térmico de uma edificação residencial unifamiliar de interesse social de acordo com RTQ-R (INSTITUTO..., 2012) e com a NBR 15575-1 (ABNT, 2013) por simulação computacional.

\section{Método}

\section{Definição da tipologia de edificação}

A tipologia analisada compreende uma habitação de interesse social fictícia, de 50,2 $\mathrm{m}^{2}$, com sala e cozinha conjugadas, dois quartos e banheiro, como mostra a Figura 1.

As análises foram feitas para o clima de Florianópolis, SC, que compreende a Zona Bioclimática 3, de acordo com a NBR 15220-3 (ABNT, 2005).

\section{Figura 1 - Tipologia de habitação de interesse social utilizada no trabalho}
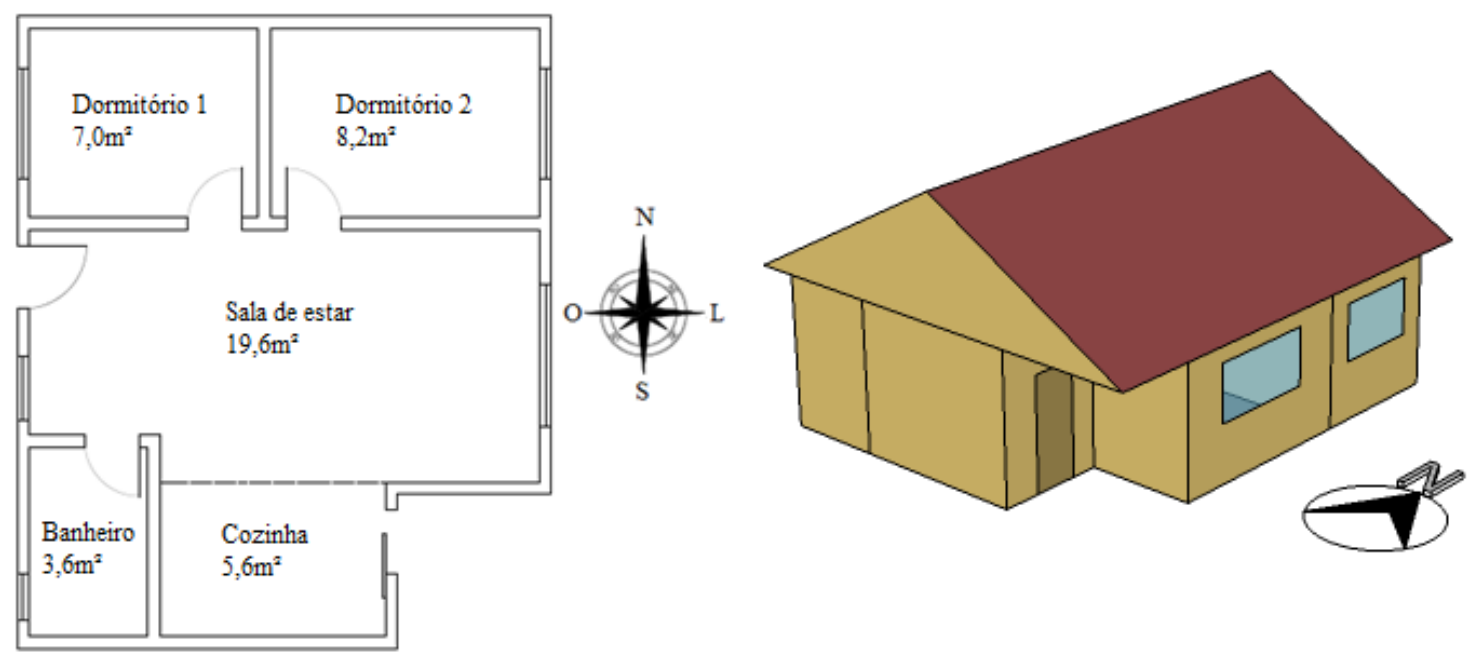
As propriedades térmicas da envoltória da edificação são parâmetros variáveis neste trabalho. As cargas internas e as rotinas de uso e ocupação foram fixadas conforme as exigências do RTQ-R ou da NBR 15575-1, que são distintas.

\section{Casos base para cada método analisado}

Este item especifica as configurações e parâmetros fixos do RTQ-R e da NBR 15575-1. Foi utilizado o programa de simulação termoenergética EnergyPlus versão 7.2 para as análises deste trabalho. O programa é recomendado pela NBR 15575-1 e atende a todas as exigências do RTQ-R para a ferramenta de simulação.

\section{RTQ-R}

O método de avaliação do RTQ-R é descrito detalhadamente em Inmetro (INSTITUTO..., 2012). Ressalta-se que este trabalho analisa o desempenho térmico da envoltória, sem considerar os pré-requisitos específicos.

A edificação foi avaliada pelos graus-hora de resfriamento, consumo relativo de energia com aquecimento de todos os ambientes de permanência prolongada e consumo com resfriamento dos dormitórios, conforme exige o RTQ-R. Foi mantido o termo "consumo com resfriamento" por ser tecnicamente mais adequado, em vez do termo "consumo com refrigeração", utilizado pelo RTQ-R.

Para a avaliação, é necessária a elaboração de dois modelos-base: (1) um naturalmente ventilado e outro (2) naturalmente ventilado durante o dia e artificialmente condicionado durante a noite. Portanto, os consumos de energia são referentes ao período noturno.

Foram respeitadas todas as configurações de cargas internas, ventilação natural, condicionamento de ar e rotinas de uso e ocupação do RTQ-R. As rotinas de ocupação foram adotadas conforme a Figura 2, com dois habitantes por dormitório. A densidade de potência instalada é de $5 \mathrm{~W} / \mathrm{m}^{2}, 6 \mathrm{~W} / \mathrm{m}^{2}$ e $1,5 \mathrm{~W} / \mathrm{m}^{2}$ para iluminação da sala/cozinha, iluminação dos quartos e densidade de potência com equipamentos na sala/cozinha, respectivamente.

\section{NBR 15575-1}

A avaliação do desempenho térmico da NBR 15575-1 (ABNT, 2013) é separada em situações de verão e inverno, definidas por um dia típico de projeto, conforme exigido pela norma.

A edificação deve ser modelada sem cargas internas, com uma troca de ar por hora (ou 1 troca/h). O consumo de energia com condicionamento de ar não é avaliado.

A norma apresenta certas configurações subjetivas, como os próprios dados para a definição do dia típico de projeto. Para a cidade de Florianópolis, SC, encontram-se na NBR 15575-1 os valores de acordo com a Tabela 1. Não se encontram, no entanto, dados de radiação solar direta, global e tipo de céu, necessários para a criação do dia típico. A nebulosidade definida na norma é uma condição de registro total de nuvens, e não necessariamente o tipo de céu. Por sua vez, o tipo de céu é representado no programa EnergyPlus como Sky Clearness, no qual 0 significa céu totalmente encoberto de nuvens e 1 significa céu limpo.

Neste trabalho adotou-se um tipo de céu complementar à nebulosidade informada, sendo, portanto, 0,3 para o verão e 0,4 para o inverno (convertendo-se os valores para a mesma ordem de grandeza), mesmo sendo uma correlação incorreta. Mais estudos devem ser realizados considerando o tipo de céu como uma incerteza, tendo em vista que não é especificado pela norma.

Figura 2 - Rotinas de ocupação fixadas pelo RTQ-R

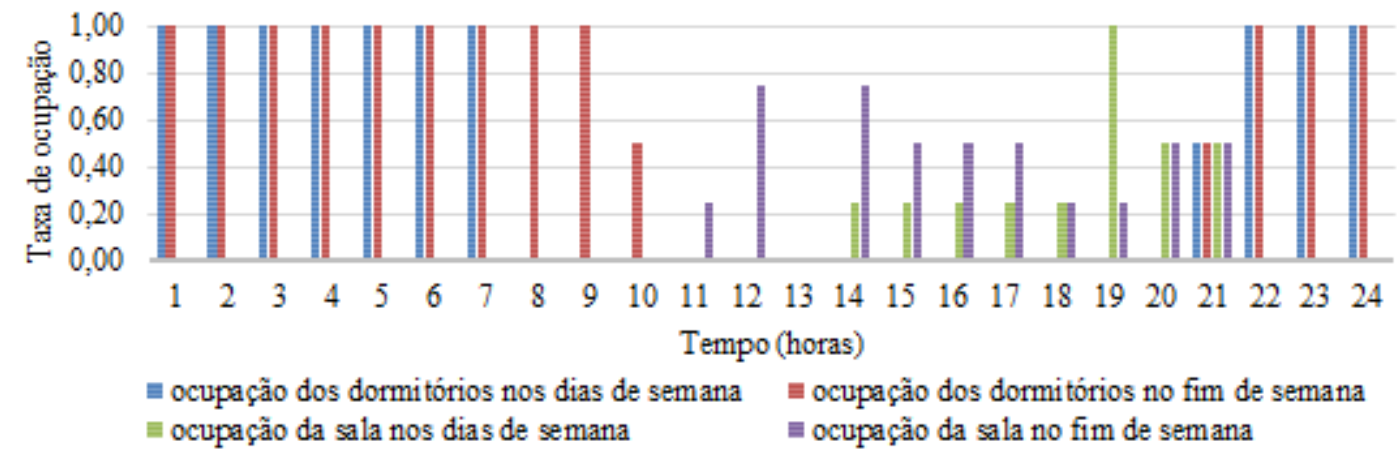

Fonte: Inmetro (INSTITUTO..., 2012). 
Tabela 1 - Configurações para os dias típicos de verão e inverno para Florianópolis, SC

\begin{tabular}{l|r|l|r}
\hline \multicolumn{2}{c|}{ Dia típico de verão } & \multicolumn{2}{c}{ Dia típico de inverno } \\
\hline Temperatura máxima diária & $32,7^{\circ} \mathrm{C}$ & Temperatura mínima diária & $6,0^{\circ} \mathrm{C}$ \\
Amplitude diária de temperatura & $6,6^{\circ} \mathrm{C}$ & Amplitude diária de temperatura & $7,4^{\circ} \mathrm{C}$ \\
Temperatura de bulbo úmido & $24,4^{\circ} \mathrm{C}$ & Temperatura de bulbo úmido & $13,4^{\circ} \mathrm{C}$ \\
Nebulosidade décimos & 7 & Nebulosidade décimos & 6 \\
\hline
\end{tabular}

Fonte: ABNT (2013).

O EnergyPlus utiliza os dados da Tabela 1 para a criação de um dia completo com dados climáticos horários. Para o perfil de temperaturas, o EnergyPlus utiliza o método Clear Sky Model, definido no Handbook of Fundamentals (AMERICAN..., 2005).

A NBR 15575-1 permite a consideração de alternativas no caso do não atendimento ao requisito mínimo no verão. Para isso, três modelos adicionais podem ser simulados:

(a) modelo com 5 trocas $/ \mathrm{h}$;

(b) modelo com veneziana nas aberturas que possa reduzir em $50 \%$ a radiação direta incidente; $\mathrm{e}$

(c) modelo que combine 5 trocas/h e a veneziana.

\section{Grupos de simulação}

Os Grupos 1 e 2 da Tabela 2 mostram os modelosbase utilizados para a avaliação pelo RTQ-R. Os Grupos 3 a 6 mostram os modelos-base para a avaliação pela NBR 15575-1. Cada grupo é avaliado por meio de 500 simulações aleatórias, 3.000 simulações no total.

\section{Temperatura do solo}

A temperatura do solo foi determinada com o programa Slab, vinculado ao EnergyPlus, cuja iteração depende diretamente da temperatura média do ar interno da edificação. Para se obter uma comparação mais precisa, todos os seis grupos da Tabela 2 foram simulados duas vezes:

(a) as primeiras 3.000 simulações foram utilizadas para a obtenção das temperaturas médias mensais do ar interno da edificação, cujo contato do solo foi considerado sob uma condição isolada. Essa condição inicial evita a realização de iterações, ou seja, simulações adicionais até a convergência da temperatura interna, e é recomendada pelo manual do Slab (ENERGYPLUS, 2012);

(b) as 3.000 simulações seguintes foram realizadas considerando-se as temperaturas médias mensais do ar interno incluídas nos objetos do Slab, para a obtenção das variáveis descritas no item "Variáveis dependentes". Neste caso, retirouse a condição isolada e calcularam-se as temperaturas referentes ao solo.

Cada simulação individual foi contemplada com a temperatura do solo inerente a suas próprias propriedades térmicas da envoltória e suas condições de cargas internas.

\section{Variáveis dependentes}

Para o RTQ-R, as variáveis dependentes são as temperaturas operativas horárias, e o consumo de energia com aquecimento e resfriamento noturno. A partir desses dados, calculam-se os graus-hora de resfriamento de acordo com a Equação 1, e o consumo relativo com aquecimento e resfriamento, com as Equações 2 e 3.

GHR $=\sum_{i=0}^{8760}\left\{\begin{array}{lr}\text { se } T_{i}>26 ; & \left(T_{i}-26\right) \\ \text { se } T_{i} \leq 26 ; & (0)\end{array}\right.$

Eq. 1

Onde:

GHR - graus-hora de resfriamento $\left({ }^{\circ} \mathrm{Ch}\right)$;

$T_{i}$ - temperatura operativa em cada uma das 8.760 horas do ano $\left({ }^{\circ} \mathrm{C}\right)$.

$$
\begin{aligned}
C A & =\sum_{i=1}^{8760} \frac{C A_{i}}{A U a m b} \\
C R & =\sum_{i=0}^{8760} \frac{C R_{i}}{A U a m b}
\end{aligned}
$$

Onde:

$C A$ - consumo relativo com aquecimento $\left(\mathrm{kWh} / \mathrm{m}^{2}\right.$.ano);

$C A_{i}$ - consumo horário com aquecimento em cada uma das 8.760 horas do ano (kWh);

$C R$ - consumo relativo com resfriamento $\left(\mathrm{kWh} / \mathrm{m}^{2}\right.$.ano);

$C R_{i}$ - consumo horário com resfriamento em cada uma das 8.760 horas do ano $(\mathrm{kWh})$; e

$A U a m b$ - área útil de cada ambiente de permanência prolongada $\left(\mathrm{m}^{2}\right)$. 
Tabela 2 - Casos-base considerados no trabalho

\begin{tabular}{c|c|c|c|l|c}
\hline Modelo & Tipo & Análise & Norma & \multicolumn{1}{c|}{ Observações } & Simulações \\
\hline Grupo1 & Ano completo & GHR & RTQ-R & Ventilação natural & 500 \\
Grupo2 & Ano completo & CA e CR & RTQ-R & Condicionamento artificial & 500 \\
Grupo3 & Dia típico & Temperatura & NBR 15575-1 & 1 troca/h e sem veneziana & 500 \\
Grupo4 & Dia típico & Temperatura & NBR 15575-1 & 5 trocas/h e sem veneziana & 500 \\
Grupo5 & Dia típico & Temperatura & NBR 15575-1 & 1 troca/h e com veneziana 50\% & 500 \\
Grupo6 & Dia típico & Temperatura & NBR 15575-1 & 5 trocas/h e com veneziana 50\% & 500 \\
\hline
\end{tabular}

Nota: “veneziana 50\%” significa veneziana capaz de reduzir em $50 \%$ a radiação direta incidente, GHR significa graushora de resfriamento, CA significa consumo relativo com aquecimento, e CR significa consumo relativo com resfriamento, a serem definidos no item "Variáveis dependentes".

Para a NBR 15575-1, as variáveis dependentes são as temperaturas do ar interno e as temperaturas de bulbo seco externas. Para o verão, calcula-se a diferença entre a máxima temperatura do ar interno e a máxima temperatura de bulbo seco externa; para o inverno, calcula-se a diferença entre a mínima temperatura do ar interno e a mínima temperatura de bulbo seco externa (Equações $4 \mathrm{e}$ 5).

$$
\begin{aligned}
& \Delta T \text { verão }=T i_{\text {máx }}-T B S_{\text {máx }} \\
& \Delta \text { Tinverno }=T i_{\text {min }}-T B S_{\text {míxn }}
\end{aligned}
$$

Onde (todos os parâmetros são em ${ }^{\circ} \mathrm{C}$ ):

$\Delta$ Tverão - diferença de temperatura para o verão;

$\Delta$ Tinverno - diferença de temperatura para o inverno;

$T B S_{\text {máx }}$ - temperatura de bulbo seco externa máxima do dia típico de verão;

$T i_{\text {máx }}$ - temperatura do ar interno máxima, para cada ambiente no dia típico de verão;

$T B S_{\text {min }}$ - temperatura de bulbo seco externa mínima do dia típico de inverno; e

$T i_{m i n}$ - temperatura do ar interno mínima para cada ambiente no dia típico de inverno.

A Tabela 3 apresenta os valores-limite aplicáveis para a classificação por ambos os métodos, válida para o arquivo climático Test Reference Year (TRY) de Florianópolis, no caso do RTQ-R, e para a Zona Bioclimática 3, no caso da NBR 15575-1.

Sabe-se que ambos os métodos são incomparáveis diretamente; no entanto, este trabalho propõe três cenários de comparação entre os níveis de desempenho do RTQ-R e da NBR 15575-1. O primeiro cenário compara os níveis $\mathrm{A}, \mathrm{B}$ e $\mathrm{C}$ do RTQ-R com o Mínimo, Intermediário e Superior da NBR 15575-1 respectivamente. Já os níveis D e E do RTQ-R correspondem ao "Não atendido" da NBR 15575-1.

O segundo cenário compara os níveis $\mathrm{A}$ e $\mathrm{E}$ do RTQ-R como sendo o Superior e o Mínimo da NBR 15575-1 respectivamente. Os níveis B, C e D correspondem ao Intermediário, e o não atendimento à norma não entraria nessa comparação. O terceiro cenário considera o nível A como Superior, os níveis B e C como Intermediário, o D como Mínimo, e o E como "Não atendido".

\section{Variáveis independentes do experimento}

Os parâmetros físicos, isto é, variáveis independentes, foram amostrados visando encontrar resultados diversificados em relação ao desempenho térmico, e são mostrados na Tabela 4.

Foi utilizado o hipercubo latino para a geração de vetores aleatórios conforme a distribuição de probabilidades de cada parâmetro. $\mathrm{O}$ intervalo de variação é dividido em iguais estratos de probabilidades, e o mesmo número de pontos é tomado para cada estrato (MELO, 2012). O método foi utilizado com sucesso por diversos autores em simulação computacional de edificações, como Hopfe e Hensen (2011) e Heo, Choudhary e Augenbroe (2012).

Como o número de simulações independe do número de parâmetros, o hipercubo latino foi utilizado para gerar 500 combinações aleatórias por meio do programa Simlab 2.2, cujo valor excede as 80 simulações recomendadas por Macdonald e Strachan (2001).

A transmitância e a capacidade térmica das paredes e coberturas foram variadas discretamente, representando a variedade de componentes construtivos que poderia haver em uma habitação de interesse social. Os valores mínimos, médios e máximos têm probabilidade de ocorrência de $20 \%$, $60 \%$ e $20 \%$ respectivamente.

A absortância solar das paredes foi considerada como uma distribuição normal de média 0,50 e o desvio padrão de 0,14 , que representa um intervalo de confiança de $99 \%$ de 0,15 a 0,85 . Para a cobertura, a média é de 0,50 e o desvio padrão de 
0,15 , que representa um intervalo de confiança de $99 \%$ de 0,10 a 0,90 .

Os vidros foram variados em relação à transmitância térmica em uma distribuição discreta, com $20 \%$ e $80 \%$ de probabilidade de ocorrência no primeiro e segundo valor respectivamente. A orientação solar foi variada através da rotação de $90^{\circ}$ de azimute em relação ao norte apontado na Figura 1, em uma distribuição discreta de mesma probabilidade de ocorrência.

A relação entre a área de abertura e a área útil do ambiente variou em 5\%, $10 \%$ e $15 \%$, em uma distribuição discreta, com $25 \%, 50 \%$ e $25 \%$ de probabilidade de ocorrência respectivamente. O fator de ventilação representa a fração real da janela que possibilita a ventilação natural, adotada de $45 \%$ a $90 \%$ da área total de abertura, em uma distribuição triangular de probabilidades.

Todas as probabilidades assumidas, no caso das variáveis discretas, foram definidas visando a uma maior ocorrência do valor central na amostragem aleatória. Essa tendência central é conhecida na distribuição normal contínua e foi uma alternativa no caso das distribuições discretas. As distribuições de probabilidades utilizadas são mostradas na Figura 3.

Tabela 3 - Limites aplicáveis para a classificação da eficiência energética da edificação, no RTQ-R e na NBR 15575-1

\begin{tabular}{|c|c|c|c|c|c|c|c|c|c|}
\hline \multicolumn{4}{|c|}{ RTQ-R } & \multicolumn{3}{|c|}{ NBR 15575-1 } & \multirow{2}{*}{\multicolumn{3}{|c|}{$\begin{array}{c}\text { Comparação } \\
\text { Cenário }\end{array}$}} \\
\hline \multirow{2}{*}{ Nível } & \multirow{2}{*}{ GHR $\left({ }^{\circ} \mathrm{Ch}\right)$} & \multirow{2}{*}{$\begin{array}{c}\text { CR } \\
\left(\mathbf{k W h} / \mathbf{m}^{2} \cdot \text { ano }\right)\end{array}$} & \multirow{2}{*}{$\begin{array}{c}\text { CA } \\
\left(\mathbf{k W h} / \mathbf{m}^{2} \cdot \text { ano }\right)\end{array}$} & \multirow{2}{*}{ Nível } & \multirow{2}{*}{$\begin{array}{c}\Delta \text { Tverão } \\
\left({ }^{\circ} \mathrm{C}\right)\end{array}$} & \multirow{2}{*}{$\begin{array}{c}\Delta \text { tinverno } \\
\left({ }^{\circ} \mathrm{C}\right)\end{array}$} & & & \\
\hline & & & & & & & 1 & 2 & 3 \\
\hline A & $<822$ & $<6,890$ & $<6,429$ & $\mathrm{~S}$ & -4 & 7 & $\mathrm{~A}=\mathrm{S}$ & $\mathrm{A}=\mathrm{S}$ & $\mathrm{A}=\mathrm{S}$ \\
\hline B & $822-1643$ & $6,890-12,284$ & $6,429-12,858$ & I & -2 & 5 & $\mathrm{~B}=\mathrm{I}$ & $\mathrm{B}=\mathrm{I}$ & $\mathrm{B}=\mathrm{I}$ \\
\hline $\mathrm{C}$ & $1643-2465$ & $12,284-17,677$ & $12,858-19,287$ & M & 0 & 3 & $\mathrm{C}=\mathrm{M}$ & $\mathrm{C}=\mathrm{I}$ & $\mathrm{C}=\mathrm{I}$ \\
\hline $\mathrm{D}$ & $2465-3286$ & $17-677-23,071$ & $19,287-25,716$ & $X$ & $>0$ & $<3$ & $\mathrm{D}=\mathrm{X}$ & $\mathrm{D}=\mathrm{I}$ & $\mathrm{D}=\mathrm{M}$ \\
\hline $\mathrm{E}$ & $>3286$ & $>23,071$ & $>25,716$ & & & & $E=X$ & $E=M$ & $E=X$ \\
\hline
\end{tabular}

Nota: ressalta-se que a comparação entre cenários é utilizada somente nas análises de concordância e diferença entre os equivalentes numéricos do item "Comparação entre os resultados dos métodos".

Legenda:
S: Superior;
I: Intermediário;
M: Mínimo; e
X: Não atendido na NBR 15575-1.

Tabela 4 - Parâmetros físicos variados nas análises

\begin{tabular}{r|c|c|c|c}
\hline Parâmetro & Símbolo & Unidade & Média/níveis & $\begin{array}{c}\text { Desvio padrão/ } \\
\text { probabilidade }\end{array}$ \\
\hline Transmitância térmica da cobertura & Ucob & $\mathrm{W} / \mathrm{m}^{2} . \mathrm{K}$ & $0,83 / 2,17 / 4,11$ & $0,2 / 0,6 / 0,2$ \\
\hline Capacidade térmica da cobertura & $\mathrm{CTcob}$ & $\mathrm{kJ} / \mathrm{m}^{2} \cdot \mathrm{K}$ & $20 / 120 / 250$ & $0,2 / 0,6 / 0,2$ \\
\hline Absortância solar da cobertura & $\alpha$ cob $^{*}$ & - & 0,50 & 0,15 \\
\hline Emissividade da cobertura & $\varepsilon c o b$ & - & $0,10 / 0,90$ & $0,25 / 0,75$ \\
\hline Transmitância térmica das paredes & Upar & $\mathrm{W} / \mathrm{m}^{2} \cdot \mathrm{K}$ & $1,00 / 2,38 / 3,70$ & $0,2 / 0,6 / 0,2$ \\
\hline Capacidade térmica das paredes & $\mathrm{CTpar}$ & $\mathrm{kJ} / \mathrm{m}^{2} \cdot \mathrm{K}$ & $49,9 / 140,0 / 250,1$ & $0,2 / 0,6 / 0,2$ \\
\hline Absortância solar das paredes & $\alpha p a r *$ & - & 0,50 & 0,14 \\
\hline Área de abertura pela área útil do ambiente & Fab & - & $0,05 / 0,10 / 0,15$ & $0,25 / 0,50 / 0,25$ \\
\hline Fator de ventilação das aberturas & Fvent** & - & $0,45 / 0,50 / 0,90$ & variável \\
\hline Orientação solar & Solar & graus & $0 \% / 90 \% / 1800^{\circ} / 270^{\circ}$ & $0,25 / 0,25 / 0,25 / 0,25$ \\
\hline Transmitância térmica dos vidros & Uvid & - & $5,36 / 6,27$ & $0,20 / 0,80$ \\
\hline
\end{tabular}

Nota: *Distribuição normal de probabilidades. **Distribuição triangular de probabilidades. As demais são distribuições discretas. 
Figura 3 - Funções de densidade de probabilidade utilizadas neste trabalho
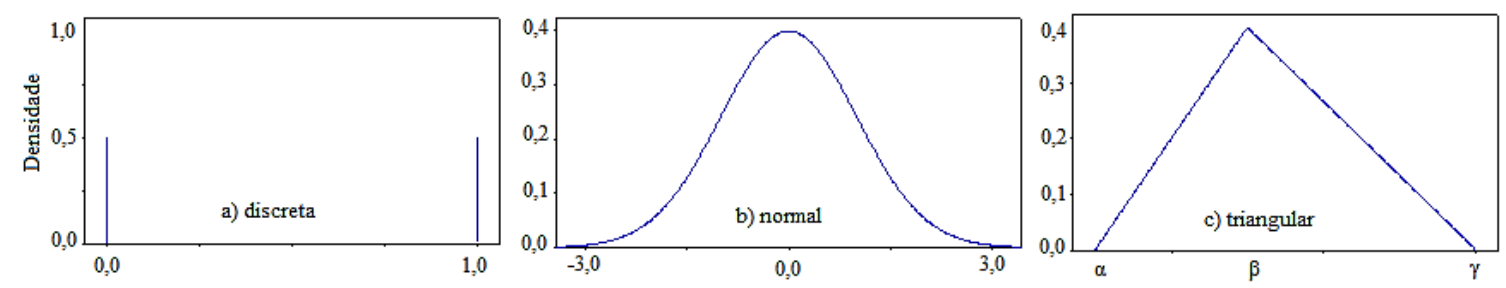

\section{Comparação entre os resultados dos métodos}

Os Grupos 1 e 2 da Tabela 2 resultaram em uma classificação do desempenho térmico da envoltória de acordo com o RTQ-R, para os graus-hora de resfriamento, consumo com aquecimento e resfriamento de cada ambiente. Já os Grupos 3 a 6 foram utilizados para encontrar uma classificação para a NBR 15575-1, para o verão e inverno de cada ambiente.

Em seu texto, a NBR 15575-1 apresenta que, caso não ocorra o atendimento do nível Mínimo para o verão em alguma simulação do Grupo 3, as configurações alternativas dos Grupos 4, 5 ou 6 podem ser utilizadas, ou seja, cada um dos casos simulados dos Grupos 4 a 6 que realmente modificaram a classificação de "Não atendido" para alguma classificação da norma (Mínimo, Intermediário ou Superior) substituíram os resultados do Grupo 3. Para o inverno, foram mantidos os resultados das simulações do Grupo 3.

$\mathrm{Na}$ impossibilidade de reportar todos os 3.000 resultados neste trabalho, foram feitas as seguintes análises:

(a) probabilidade de se alcançar determinado nível de desempenho: análise feita para cada variável dependente, cada ambiente de permanência prolongada, para o RTQ-R e a NBR 15575-1;

(b) concordância entre as classificações do RTQR e da NBR 15575-1: foi proposta uma análise de concordância entre ambos os métodos analisados. Por concordância entende-se a equivalência entre as classificações, ou seja, se apontam o mesmo nível de eficiência em cada um dos cenários da Tabela 3. Os graus-hora de resfriamento e o consumo com resfriamento foram comparados com os resultados de verão da NBR 15575-1, enquanto os resultados de consumo com aquecimento do RTQ-R foram comparados com os resultados de inverno da NBR 15575-1;

(c) análise de sensibilidade dos parâmetros: é comparada a ordem dos parâmetros mais influentes de cada método em cada variável dependente. Para a análise de sensibilidade foi utilizado o método de
Coeficientes de Regressão Padronizados com o programa Simlab 2.2. A análise de sensibilidade, neste trabalho, tem por objetivo verificar se a concepção dos métodos de simulação analisados é semelhante; e

(d) análise dos casos individuais com maior diferença entre os níveis de desempenho: são comparados os casos com maior diferença entre as classificações obtidas, independentemente de cada cenário da Tabela 3. Para cada caso individual, são relatadas as configurações de seus parâmetros termofísicos da Tabela 4.

\section{Resultados}

\section{Níveis de desempenho}

A Tabela 5 mostra os níveis de desempenho alcançados no verão para cada ambiente e para cada um dos grupos (G3 a G6) da NBR 15575-1. Percebe-se que as simulações do Grupo 4 (com 5 trocas/h) pioraram as classificações em relação ao Grupo 3 em muitos casos. Os melhores resultados foram obtidos com o Grupo 5 (veneziana 50\%), que apresentam maiores percentuais de casos acima do nível Intermediário.

As simulações do Grupo 4 melhoraram a classificação de 46 dos 500 casos no verão em relação ao Grupo 3. As simulações do Grupo 5 melhoraram a classificação de 98 casos. As simulações do Grupo 6 (5 trocas/h e veneziana $50 \%$ ) melhoraram a classificação de 58 casos. Dessa forma, todas as análises da NBR 15575-1 deste trabalho foram feitas unindo as classificações para estes últimos 98 casos do Grupo 5 e os demais resultados referentes ao Grupo 3, para o verão.

A Figura 4 mostra o percentual de casos (em relação aos 500) que atingiram cada um dos níveis de desempenho de acordo com o RTQ-R (Figura 4a) e a NBR 15575-1 (Figura 4b).

Percebe-se que os níveis obtidos para os graushora de resfriamento do RTQ-R são baixos na maior parte dos casos. O nível E é atingido de $59 \%$ a $69 \%$ dos casos entre os ambientes. 
O mesmo ocorre para o consumo com resfriamento, em que de $59 \%$ a $70 \%$ dos casos atinge nível E. Nenhum caso atinge nível A para o consumo com resfriamento nos dormitórios, e de $1,2 \%$ a $1,4 \%$ dos casos (6 a 7) atingiram nível $\mathrm{A}$ para os graus-hora de resfriamento.

Para o consumo com aquecimento, a maior parte dos casos atinge nível B nos dormitórios (de $32 \%$ a $33 \%$ ). Para a sala, a maior parte atinge nível $\mathrm{E}$ (58\%). O RTQ-R não considera o consumo com resfriamento da sala.

Para a NBR 15575-1, a maior parte dos casos atingiu o nível Mínimo para o verão (de $57 \%$ a $67 \%$ entre os ambientes). Já para o inverno, a maior parte dos casos não atendeu à norma (de $62 \%$ a $65 \%)$. De 2 a 4 casos $(0,4 \%$ a $0,6 \%)$ atingiram o nível Superior para o verão. Nenhum caso atingiu nível Superior no inverno.
O mesmo ocorre para o consumo com resfriamento, em que de $59 \%$ a $70 \%$ dos casos atinge nível E. Nenhum caso atinge nível A para o consumo com resfriamento nos dormitórios, e de $1,2 \%$ a $1,4 \%$ dos casos (6 a 7) atingiram nível $\mathrm{A}$ para os graus-hora de resfriamento.

Para o consumo com aquecimento, a maior parte dos casos atinge nível B nos dormitórios (de 32\% a $33 \%$ ). Para a sala, a maior parte atinge nível $\mathrm{E}$ (58\%). O RTQ-R não considera o consumo com resfriamento da sala.

Para a NBR 15575-1, a maior parte dos casos atingiu o nível Mínimo para o verão (de $57 \%$ a $67 \%$ entre os ambientes). Já para o inverno, a maior parte dos casos não atendeu à norma (de $62 \%$ a $65 \%)$. De 2 a 4 casos $(0,4 \%$ a $0,6 \%)$ atingiram o nível Superior para o verão. Nenhum caso atingiu nível Superior no inverno.

Tabela 5 - Nível de desempenho no verão em cada um dos grupos da NBR 15575-1

\begin{tabular}{c|cccc|ccccccccc}
\hline \multirow{2}{*}{ Nível } & G3 & G4 & G5 & G6 & G3 & G4 & G5 & G6 & G3 & G4 & G5 & G6 \\
\cline { 2 - 13 } & \multicolumn{3}{|c|}{ Dormitório 1 } & & \multicolumn{6}{c|}{ Dormitório 2 } & & \multicolumn{3}{c}{ Sala } & \\
\hline Não atende & $11 \%$ & $6 \%$ & $8 \%$ & $5 \%$ & $11 \%$ & $6 \%$ & $9 \%$ & $4 \%$ & $12 \%$ & $7 \%$ & $9 \%$ & $5 \%$ \\
Mínimo & $50 \%$ & $82 \%$ & $45 \%$ & $76 \%$ & $50 \%$ & $83 \%$ & $45 \%$ & $77 \%$ & $53 \%$ & $89 \%$ & $48 \%$ & $87 \%$ \\
Intermediário & $38 \%$ & $12 \%$ & $45 \%$ & $19 \%$ & $38 \%$ & $12 \%$ & $45 \%$ & $19 \%$ & $34 \%$ & $4 \%$ & $42 \%$ & $8 \%$ \\
Superior & $1 \%$ & $0 \%$ & $2 \%$ & $0 \%$ & $1 \%$ & $0 \%$ & $2 \%$ & $0 \%$ & $0 \%$ & $0 \%$ & $1 \%$ & $0 \%$ \\
\hline
\end{tabular}

Figura 4 - Classificações obtidas com RTQ-R (a) e com a NBR 15575-1 (b)

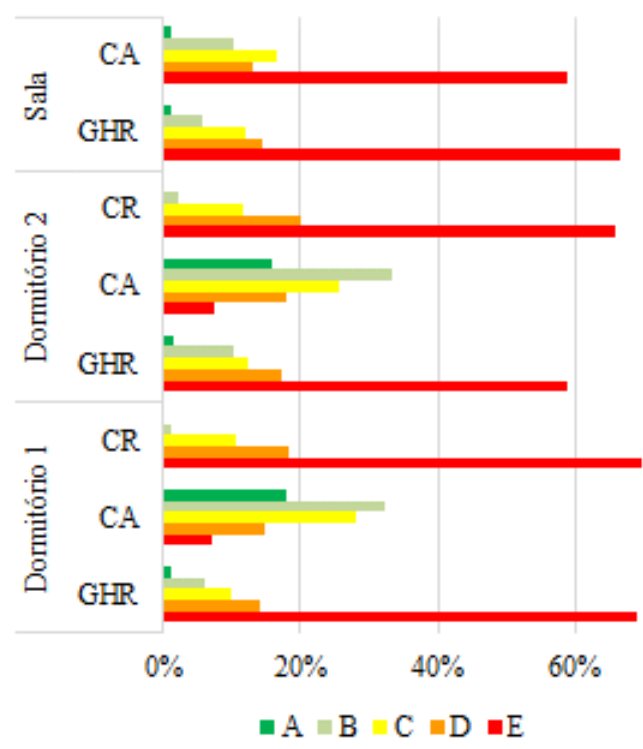

a) RTQ-R

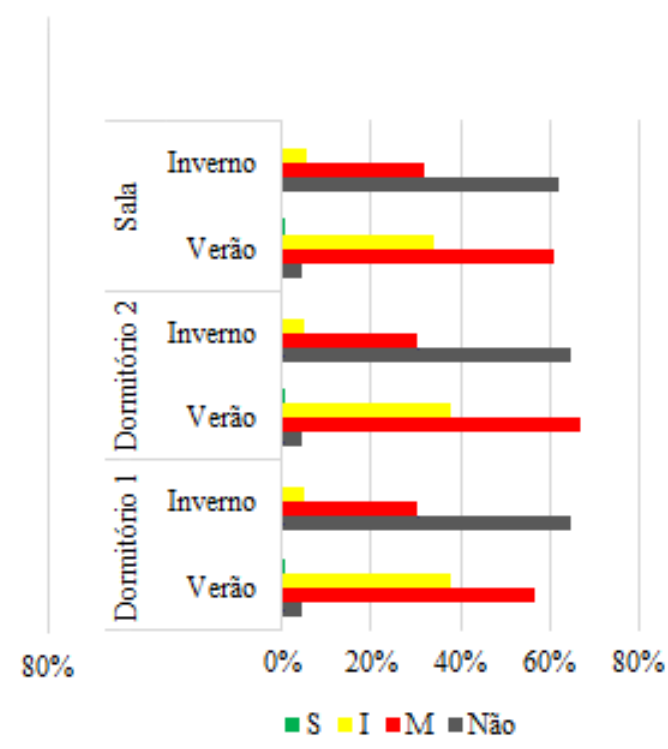

b) NBR 15575

Nota: Legenda:

M - Mínimo;

I - Intermediário;

$\mathrm{S}$ - Superior; e

Não - Não atende à norma. 
A Figura 5 mostra os resultados das simulações com o RTQ-R. A Figura 6 mostra os resultados para as simulações da NBR 15575-1.

Os graus-hora de resfriamento (Figura 5) variaram de $299{ }^{\circ} \mathrm{Ch}$ até $13.932{ }^{\circ} \mathrm{Ch}$, mesmo com baixas probabilidades de ocorrência nos valores extremos. Já nos casos da Figura 6, o $\Delta$ Tverão variou de $-4,2$ ${ }^{\circ} \mathrm{C}$ a $2,6{ }^{\circ} \mathrm{C}$. Estse tipo de análise pode ser utilizado na determinação de intervalos de classificação do nível de desempenho da edificação, uma vez que combinações aleatórias foram realizadas procurando obter a maior diversidade de casos possível. Por exemplo, o intervalo de $299{ }^{\circ} \mathrm{Ch}$ a $13.932{ }^{\circ} \mathrm{Ch}$ pode ser dividido em 4 estratos, representando os níveis A a E de desempenho.

\section{Análise de concordância em cada cenário}

A Tabela 6 apresenta a concordância entre os métodos estudados, em que "Não" significa que não concordam exatamente no nível de desempenho, e "Sim" que concordam. Ressalta-se que está sendo avaliada a conjugação do Grupo 3 com o Grupo 5, no caso da NBR 15575-1.

Figura 5 - Resultados das simulações pelo RTQ-R
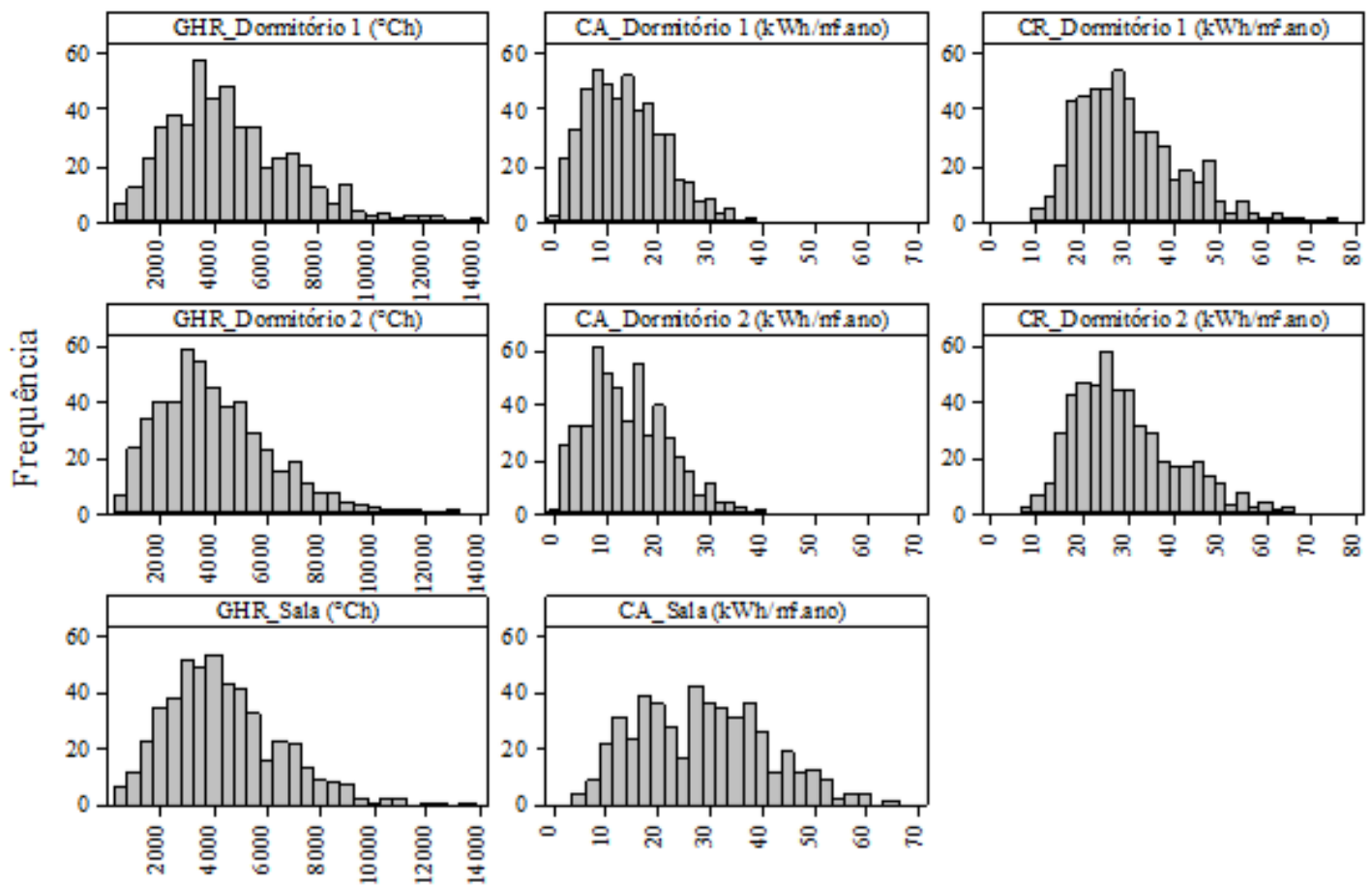

Figura 6 - Resultados das simulações pela NBR 15575-1

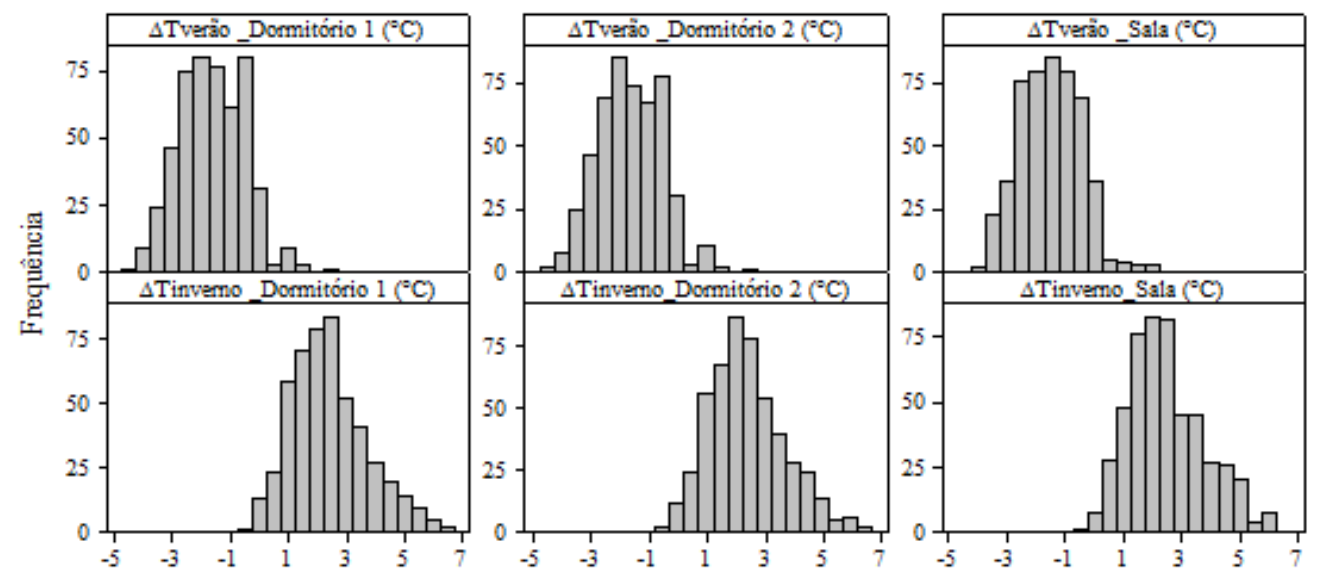


Tabela 6 - Percentual dos casos que concordam ou não no nível de desempenho em cada um dos cenários analisados

\begin{tabular}{|c|c|c|c|c|c|c|c|c|c|}
\hline \multirow[b]{2}{*}{ Cenário } & \multirow[b]{2}{*}{$\begin{array}{c}\text { Concordam } \\
?\end{array}$} & \multicolumn{3}{|c|}{ Dormitório l } & \multicolumn{3}{|c|}{ Dormitório 2} & \multicolumn{2}{|c|}{ Sala } \\
\hline & & $\begin{array}{c}\text { GHR do } \\
\text { RTQ-R } \\
\times \\
\text { verão da } \\
\text { NBR } \\
\text { 15575-1 }\end{array}$ & $\begin{array}{c}\text { CR do } \\
\text { RTQ-R } \\
\times \\
\text { verão da } \\
\text { NBR } \\
15575-1\end{array}$ & $\begin{array}{c}\text { CA do } \\
\text { RTQ-R } \\
\times \\
\text { inverno } \\
\text { da NBR } \\
\text { 15575-1 }\end{array}$ & $\begin{array}{c}\text { GHR do } \\
\text { RTQ-R } \\
\times \\
\text { verão da } \\
\text { NBR } \\
15575-1\end{array}$ & $\begin{array}{c}\text { CR do } \\
\text { RTQ-R } \\
\times \\
\text { verão da } \\
\text { NBR } \\
15575-1\end{array}$ & $\begin{array}{c}\text { CA do } \\
\text { RTQ-R } \\
\times \\
\text { inverno } \\
\text { da NBR } \\
\text { l5575-1 }\end{array}$ & $\begin{array}{l}\text { GHR do } \\
\text { RTQ-R } \\
\times \\
\text { verão da } \\
\text { NBR } \\
15575-1\end{array}$ & $\begin{array}{c}\text { CA do } \\
\text { RTQ-R } \\
\times \\
\text { inverno } \\
\text { da NBR } \\
\text { 15575-1 }\end{array}$ \\
\hline \multirow{2}{*}{1} & Não & $89,0 \%$ & $91,6 \%$ & $78,2 \%$ & $83,6 \%$ & $89,8 \%$ & $74,6 \%$ & $88,8 \%$ & $19,4 \%$ \\
\hline & $\operatorname{Sim}$ & $11,0 \%$ & $8,4 \%$ & $21,8 \%$ & $16,4 \%$ & $10,2 \%$ & $25,4 \%$ & $11,2 \%$ & $80,6 \%$ \\
\hline \multirow{2}{*}{2} & Não & $22,6 \%$ & $45,4 \%$ & $100,0 \%$ & $23,4 \%$ & $47,0 \%$ & $100,0 \%$ & $16,8 \%$ & $93,6 \%$ \\
\hline & $\operatorname{Sim}$ & $77,2 \%$ & $54,4 \%$ & $0,0 \%$ & $76,6 \%$ & $53,0 \%$ & $0,0 \%$ & $83,0 \%$ & $6,4 \%$ \\
\hline \multirow{2}{*}{3} & Não & $91,8 \%$ & $93,4 \%$ & $93,0 \%$ & $91,8 \%$ & $94,0 \%$ & $92,6 \%$ & $91,0 \%$ & $43,0 \%$ \\
\hline & Sim & $8,2 \%$ & $6,6 \%$ & $7,0 \%$ & $8,2 \%$ & $6,0 \%$ & $7,4 \%$ & $9,0 \%$ & $56,8 \%$ \\
\hline
\end{tabular}

Para o Cenário 1, a maior parte dos casos não concordou, exceto para o consumo com aquecimento (do RTQ-R) e o inverno (da NBR 15575-1) da sala, em que 80,6\% dos casos concordaram. Já para o Cenário 2, que excluiu da análise os casos não atendidos pela NBR 15575-1, a maior parte dos casos concordou entre os graushora de resfriamento e consumo com resfriamento com o verão. No entanto, para o consumo com aquecimento e o inverno, nenhum caso concordou nos dormitórios, e 93,6\% dos casos não concordaram na sala. O Cenário 3 apresentou comportamento semelhante ao Cenário 1, no qual grande percentual não concordou nos resultados, ou seja, dois dos cenários mostraram grande falta de concordância. O Cenário 2 apenas mostrou maior concordância nas análises de verão pelo fato de o nível Intermediário da NBR 15575-1 corresponder a três níveis (B, C e D) do RTQ-R. Esse cenário foi mantido apenas como uma possível alternativa de comparação, mas os resultados comprovaram a problemática de sua utilização.

\section{Análise de sensibilidade dos parâmetros}

A Tabela 7 mostra os coeficientes de regressão padronizados para cada variável dependente. Por exemplo, no RTQ-R, ao aumentar a absortância solar da cobertura, aumentam-se os graus-hora de resfriamento, mas diminui-se o consumo com aquecimento.

Percebem-se as diferenças entre os parâmetros mais importantes nos graus-hora de resfriamento com o consumo com resfriamento (ambos do RTQ-R). A transmitância térmica da cobertura apresentou sinais contrários, indicando que uma alta transmitância ajuda a diminuir o consumo com resfriamento noturno, mas aumenta os graus-hora de resfriamento. A justificativa para o fato é que o consumo com resfriamento é computado apenas para o período noturno do dia, quando há interesse em perder a carga interna para o ambiente exterior, que é favorecido pela alta transmitância térmica da cobertura.

O mesmo acontece com a capacidade térmica das paredes. No caso do consumo com resfriamento, uma alta capacidade térmica aumenta o consumo de energia, pois o fluxo de calor é atrasado para os horários noturnos, quando há funcionamento do sistema.

Para comprovar ainda mais a veracidade do fato, pode-se comparar o consumo com resfriamento com o consumo com aquecimento (que são computados para o mesmo período do dia noturno). Percebe-se que os parâmetros apresentam sempre sinais contrários. Por exemplo, ao aumentar a capacidade térmica das paredes, aumenta-se o consumo com resfriamento, mas diminui-se o consumo com aquecimento.

Foram obtidos coeficientes de determinação $\mathrm{R}^{2}$ satisfatórios, sempre maiores que 0,82 , indicando que considerável parte da variância dos dados é explicada pelo método de análise de sensibilidade escolhido. Cabe ressaltar que coeficientes maiores seriam difíceis de se obter, tendo em vista que muitos parâmetros possuem comportamento não linear, como a transmitância térmica de paredes e coberturas (SIGNOR, 1999).

Há pouca diferença entre os parâmetros influentes para os métodos do RTQ-R e da NBR 15575-1. Apesar de a ordem dos parâmetros nos graus-hora de resfriamento e no $\Delta$ Tverão ser diferente, os grupos de parâmetros mais importantes são os mesmos: absortância solar da cobertura, transmitância térmica da cobertura, absortância 
solar das paredes (nas variações positivas) e emissividade da cobertura, capacidade térmica das paredes (nas variações negativas).

Ressalta-se que o parâmetro Fvent (fator de ventilação das aberturas) não foi computado para as variáveis dependentes da NBR 15575-1, pois o método de ventilação natural da norma não o considera.

Em comparação com o consumo de aquecimento e o $\Delta$ Tinverno, os parâmetros mais influentes são idênticos. Deve-se notar que o sinal entre essas duas variáveis dependentes é o contrário, ou seja, aumento no consumo de energia com aquecimento indicaria que a diferença entre a temperatura interna e a externa ( $\Delta$ Tinverno) está baixa.

\section{Análise de casos individuais}

A Tabela 8 mostra a configuração dos parâmetros para os 15 casos que apresentaram maior discordância entre o RTQ-R e a NBR 15575-1, considerando os Cenários 1 e 3 . A Tabela 9 mostra os níveis de desempenho de cada um desses 15 casos.

Tabela 7 - Coeficientes de Regressão Padronizados dos parâmetros em cada variável dependente e o coeficiente de determinação $R^{2}$ da regressão

\begin{tabular}{|c|c|c|c|c|c|c|c|c|c|}
\hline \multicolumn{2}{|c|}{ GHR } & \multicolumn{2}{|c|}{$\mathbf{C R}$} & \multicolumn{2}{|c|}{$\Delta$ Tverão } & \multicolumn{2}{|c|}{ CA } & \multicolumn{2}{|c|}{$\Delta$ Tinverno } \\
\hline$\alpha \mathrm{cob}$ & 0,5750 & CTpar & 0,3453 & $a c o b$ & 0,4403 & $\varepsilon c o b$ & $0,6(454$ & CTpar & 0,3237 \\
\hline$\alpha p a r$ & 0,4070 & $\alpha \operatorname{cob}$ & 0,3430 & Ucob & 0,3375 & Ucob & 0,5692 & CTcob & 0,2136 \\
\hline Ucob & 0,3940 & CTcob & $0,2 \$ 75$ & apar & 0,3307 & Upar & 0,3239 & $\alpha c o b$ & 0,0765 \\
\hline Uvid & 0,0992 & apar & 0,2434 & Upar & 0,2486 & Somb & 0,0724 & apar & 0,0466 \\
\hline Upar & $0,0 \$ 30$ & Uvid & 0,0671 & Uvid & 0,0709 & $\mathrm{Fab}$ & 0,0295 & Uvid & $0,0 \$ 30$ \\
\hline Solar & $-0,0311$ & $\mathrm{Fab}$ & $-0,0,126$ & Solar & 0,0343 & Solar & 0,0052 & Fab & 0,0135 \\
\hline CTcob & $-0,0909$ & Fvent & $-0,0265$ & $\mathrm{Fab}$ & $-0,0289$ & Fvent & $0,0,13$ & Solar & $0,0 \hat{\theta} 15$ \\
\hline Somb & $-0,0994$ & Solar & $-0,0490$ & Somb & $-0,1,010$ & Uvid & $-0,0290$ & Somb & $-0,0205$ \\
\hline Fvent & $-0,1110$ & Somb & $-0,0923$ & CTcob & $-0,2190$ & apar & $-0,0950$ & Upar & $-0,2790$ \\
\hline $\mathrm{Fab}$ & $-0,1690$ & Ucob & $-0,2290$ & CTpar & $-0,4,100$ & $\alpha c o b$ & $-0,1700$ & Ucob & $-0,4960$ \\
\hline CTpar & $-0,2030$ & Upar & $-0,2470$ & $\varepsilon c o b$ & $-0,4990$ & CTpar & $-0,2040$ & $\varepsilon c o b$ & $-0,5810$ \\
\hline$\varepsilon \mathrm{cob}$ & $-0,3,820$ & $\varepsilon \mathrm{cob}$ & $-0,6410$ & - & - & CTcob & $-0,2,110$ & - & - \\
\hline $\mathrm{R}^{2}$ & 0,8442 & $\mathrm{R}^{2}$ & 0,8839 & $\mathrm{R}^{2}$ & 0,8751 & $\mathrm{R}^{2}$ & 0,9012 & $\mathrm{R}^{2}$ & 0,8232 \\
\hline
\end{tabular}

Nota: os cinco parâmetros menos influentes em cada variável dependente estão destacados em fundo cinza.

Tabela 8 - Configurações dos parâmetros dos casos com maior discordância entre o RTQ-R e a NBR 15575-1 (em relação aos Cenários 1 e 3)

\begin{tabular}{cccccccccccccc}
\multirow{2}{*}{ Caso } & Ucob & CTcob & $\alpha$ cob & $\boldsymbol{z}$ Uob & Upar & \multicolumn{1}{c}{ CTpar } & \multicolumn{1}{c}{ apar } & Fab & Fvent & Somb Solar & Uvid \\
\cline { 2 - 16 } & $\left(\mathbf{W} / \mathbf{m}^{\mathbf{2}} \mathbf{K}\right)$ & $\left(\mathbf{k J} / \mathbf{m}^{2} \mathbf{K}\right)$ & - & - & $\left(\mathbf{W} / \mathbf{m}^{2} \mathbf{K}\right)$ & $\left(\mathbf{k J} / \mathbf{m}^{2} \mathbf{K}\right)$ & - & - & - & - & - & $\left(\mathbf{W} / \mathbf{m}^{2} \mathbf{K}\right)$ \\
\hline 66 & 2,17 & 250 & 0,56 & 0,90 & 2,38 & 140 & 0,56 & 0,10 & 0,50 & 1 & 1 & 5,36 \\
\hline 88 & 0,83 & 120 & 0,64 & 0,90 & 1,00 & 140 & 0,61 & 0,10 & 0,61 & 0 & 1 & 6,27 \\
\hline 112 & 2,17 & 20 & 0,72 & 0,90 & 2,38 & 250,1 & 0,40 & 0,10 & 0,48 & 0 & 4 & 6,27 \\
\hline 151 & 0,83 & 20 & 0,18 & 0,90 & 1,00 & 49,9 & 0,46 & 0,10 & 0,66 & 0 & 4 & 6,27 \\
\hline 165 & 2,17 & 250 & 0,54 & 0,90 & 1,00 & 140 & 0,44 & 0,05 & 0,56 & 0 & 2 & 6,27 \\
\hline 237 & 0,83 & 120 & 0,56 & 0,90 & 1,00 & 140 & 0,63 & 0,05 & 0,63 & 0 & 4 & 6,27 \\
\hline 266 & 2,17 & 250 & 0,39 & 0,10 & 2,38 & 250,1 & 0,47 & 0,15 & 0,68 & 1 & 1 & 6,27 \\
\hline 311 & 0,83 & 20 & 0,42 & 0,90 & 2,38 & 250,1 & 0,75 & 0,05 & 0,75 & 1 & 2 & 5,36 \\
\hline 344 & 2,17 & 20 & 0,64 & 0,90 & 1,00 & 250,1 & 0,70 & 0,10 & 0,52 & 0 & 2 & 6,27 \\
\hline 350 & 0,83 & 120 & 0,66 & 0,90 & 2,38 & 250,1 & 0,67 & 0,10 & 0,69 & 0 & 4 & 6,27 \\
\hline 387 & 0,83 & 250 & 0,60 & 0,90 & 1,00 & 140 & 0,57 & 0,10 & 0,50 & 0 & 2 & 6,27 \\
\hline 392 & 2,17 & 20 & 0,57 & 0,90 & 1,00 & 140 & 0,60 & 0,10 & 0,55 & 0 & 3 & 6,27 \\
\hline 402 & 2,17 & 120 & 0,48 & 0,90 & 1,00 & 140 & 0,56 & 0,05 & 0,72 & 0 & 2 & 6,27 \\
\hline 444 & 2,17 & 250 & 0,39 & 0,90 & 1,00 & 250,1 & 0,52 & 0,05 & 0,48 & 1 & 2 & 6,27 \\
\hline 496 & 0,83 & 20 & 0,52 & 0,90 & 2,38 & 140 & 0,51 & 0,10 & 0,47 & 0 & 2 & 5,36 \\
\hline
\end{tabular}


Tabela 9 - Nível de desempenho dos casos com maior discordância entre o RTQ-R e a NBR 15575-1 (em relação aos Cenários 1 e 3)

\begin{tabular}{|c|c|c|c|c|c|c|c|c|c|c|c|c|c|c|}
\hline \multirow{3}{*}{ Caso } & \multicolumn{5}{|c|}{\begin{tabular}{|c|} 
Dormitóriol \\
\end{tabular}} & \multicolumn{5}{|c|}{\begin{tabular}{|l} 
Dormitório2 \\
\end{tabular}} & \multicolumn{4}{|c|}{ Sala } \\
\hline & GHR & CR & verão & $\mathrm{CA}$ & inverno & GHR & CR & verão & $\mathrm{CA}$ & inverno & GHR & verão & $\mathrm{CA}$ & inverno \\
\hline & RTQ & & $\begin{array}{c}\text { NBR } \\
15575\end{array}$ & RTQ-R & $\begin{array}{c}\text { NBR } \\
15575\end{array}$ & RT & & $\begin{array}{c}\text { NBR } \\
15575\end{array}$ & RTQ-R & $\begin{array}{c}\text { NBR } \\
15575\end{array}$ & RTQ-R & \begin{tabular}{c|} 
NBR \\
15575
\end{tabular} & RTQ-R & $\begin{array}{c}\text { NBR } \\
15575\end{array}$ \\
\hline 66 & E & $E$ & I & B & $\mathrm{X}$ & E & E & I & B & $\mathrm{X}$ & E & I & E & $\mathrm{X}$ \\
\hline 88 & $E$ & $E$ & I & A & $\mathrm{M}$ & $E$ & $E$ & I & $\mathrm{A}$ & $\mathrm{M}$ & $\mathrm{D}$ & I & B & $\mathrm{M}$ \\
\hline 112 & $E$ & $E$ & I & $\mathrm{B}$ & $\mathrm{X}$ & $E$ & $E$ & I & B & $\mathrm{X}$ & $E$ & $\mathrm{M}$ & $E$ & $\mathrm{x}$ \\
\hline 151 & $\mathrm{C}$ & $\mathrm{D}$ & I & $\mathrm{A}$ & $\mathrm{X}$ & $\mathrm{D}$ & $E$ & I & $\mathrm{A}$ & $\mathrm{X}$ & $\mathrm{C}$ & I & $\mathrm{D}$ & $\mathrm{M}$ \\
\hline 165 & $E$ & $E$ & I & $\mathrm{B}$ & $\mathrm{M}$ & $E$ & $E$ & I & B & $\mathrm{M}$ & $E$ & I & $\mathrm{C}$ & $\mathrm{X}$ \\
\hline 237 & $E$ & $E$ & I & $\mathrm{A}$ & $\mathrm{M}$ & $E$ & $E$ & I & $\mathrm{A}$ & $\mathrm{M}$ & $E$ & $\mathrm{M}$ & B & $\mathrm{M}$ \\
\hline 266 & $E$ & $E$ & I & $\mathrm{A}$ & $\mathrm{M}$ & D & $E$ & I & $\mathrm{A}$ & $\mathrm{M}$ & $\mathrm{C}$ & $\mathrm{M}$ & B & I \\
\hline 311 & $E$ & $E$ & I & $\mathrm{A}$ & $\mathrm{M}$ & $E$ & $E$ & I & B & $\mathrm{M}$ & $E$ & I & $\mathrm{C}$ & $\mathrm{M}$ \\
\hline 344 & $E$ & $E$ & $\mathrm{M}$ & $\mathrm{A}$ & $\mathrm{X}$ & $E$ & $E$ & $\mathrm{M}$ & B & $\mathrm{X}$ & $E$ & $\mathrm{M}$ & D & $\mathrm{X}$ \\
\hline 350 & $E$ & $E$ & I & $\mathrm{A}$ & $\mathrm{M}$ & $E$ & $E$ & I & $\mathrm{A}$ & $\mathrm{M}$ & $E$ & I & $\mathrm{C}$ & $\mathrm{M}$ \\
\hline 387 & $E$ & $E$ & I & $\mathrm{A}$ & $\mathrm{M}$ & $E$ & $E$ & I & $\mathrm{A}$ & $\mathrm{M}$ & $E$ & I & B & $\mathrm{M}$ \\
\hline 392 & $E$ & $E$ & I & B & $\mathrm{X}$ & $E$ & $E$ & I & B & $\mathrm{X}$ & $E$ & $\mathrm{M}$ & $E$ & $\mathrm{X}$ \\
\hline 402 & $E$ & $E$ & I & B & $\mathrm{X}$ & D & $E$ & I & B & $\mathrm{X}$ & $E$ & $\mathrm{M}$ & D & $\mathrm{X}$ \\
\hline 444 & D & $E$ & $S$ & B & $\mathrm{X}$ & $\mathrm{C}$ & $E$ & I & B & $\mathrm{X}$ & $\mathrm{C}$ & I & $\mathrm{D}$ & $\mathrm{X}$ \\
\hline 496 & $E$ & $E$ & I & B & $\mathrm{X}$ & D & $E$ & I & B & $\mathrm{X}$ & $E$ & M & D & $\mathrm{X}$ \\
\hline
\end{tabular}

Nota: GHR, CA e CR são referentes ao RTQ-R, e “verão" e “inverno" são referentes à NBR 15575-1.

A grande parte dos casos atingiu níveis $\mathrm{D}$ ou $\mathrm{E}$ para os graus-hora de resfriamento pelo RTQ-R, enquanto a NBR 15575-1 resulta em nível Intermediário ou Superior para os dormitórios.

Analisando-se o caso 444, por exemplo, percebe-se que ele possui transmitância térmica da cobertura em nível médio e capacidade térmica da cobertura e das paredes em nível superior (Tabela 4). Também apresenta absortâncias médias para a cobertura e as paredes, mas com fator de abertura de 5\%. Esse caso atinge nível D pelo RTQ-R para os graus-hora de resfriamento, e nível Superior para a NBR 15575-1 no verão.

Da mesma forma, o caso 66 atinge nível B para o consumo com aquecimento, mas não atende à NBR 15575-1 para o inverno. O mesmo apresenta absortâncias solares médias para as paredes externas e a cobertura, capacidade térmica das paredes média, alta capacidade térmica na cobertura e transmitância térmica média para a parede e a cobertura.

De maneira geral, os casos que mais discordaram apresentam transmitâncias térmicas em nível mínimo ou médio, capacidade térmica das paredes em nível médio ou máximo, altas absortâncias solares e alta emissividade da cobertura.

Essas divergências podem ser explicadas por diversos motivos. O primeiro e mais evidente é a variável dependente escolhida: o RTQ-R analisa o desempenho térmico da edificação por meio de uma simulação para todas as horas do ano, quantificando os graus-hora de resfriamento e os consumos de energia com aquecimento e resfriamento. Já a NBR 15575-1, por ser mais simples, analisa somente um dia típico específico, quando é verificada a diferença entre as temperaturas internas e externas máximas no verão, e mínimas no inverno.

Em segundo lugar, o RTQ-R analisa a temperatura operativa dos ambientes, e a NBR 15575-1 analisa apenas a temperatura do ar. Outra grande diferença é a carga interna dos modelos. O RTQ-R pretende ser mais realista, ao analisar o desempenho da edificação em condições próximas das reais, com cargas de ocupação, equipamentos e iluminação representativas, com suas devidas rotinas de uso. Já a NBR 15575-1 analisa o desempenho térmico das habitações sob uma condição hipotética, de nenhuma carga interna, o que pode gerar equívocos na utilização desse modelo para outros fins.

Um possível equívoco seria utilizar o método de simulação da NBR 15575-1 para estudos de otimização do desempenho térmico. O RTQ-R já seria mais adequado, mas não o ideal para essa finalidade. Seria o mesmo equívoco de tentar dimensionar um isolamento térmico de cobertura ou mesmo um sistema de condicionamento de ar sem considerar as cargas internas da edificação.

Outra grande diferença é o cálculo da ventilação natural. O RTQ-R utiliza o método do AirflowNetwork, em que são levados em consideração os coeficientes de pressão da edificação, os coeficientes de rugosidade do 
entorno, os coeficientes de descarga e expoente de fluxo de ar das aberturas, além do fator de ventilação (GU, 2007). Já a NBR 15575-1 considera uma troca de ar por hora fixa, semelhante a uma taxa de infiltração.

Ao todo, dois ambientes apresentaram a máxima discordância no inverno, onde o RTQ-R resulta em nível $\mathrm{A}$, mas não atende à NBR 15575-1. Outros 134 ambientes também apresentaram discordância no inverno, obtendo nível A pelo RTQ-R e Mínimo pela NBR 15575-1, ou B pelo RTQ-R e Não atende pela NBR 15575-1.

No caso do verão, a discordância foi menor, quando um ambiente apresentou a máxima discordância, obtendo nível D para o RTQ-R e nível Superior pela NBR 15575-1. Outros 66 ambientes apresentaram discordância no verão, obtendo nível E para o RTQ-R e nível Intermediário para a NBR 15575-1.

\section{Conclusões}

Este trabalho apresentou uma comparação entre os métodos brasileiros de avaliação do desempenho térmico de edificações residenciais: o RTQ-R e a NBR 15575-1. Uma edificação unifamiliar de interesse social foi analisada para o clima de Florianópolis, SC.

Percebe-se que os métodos podem ou não conduzir a resultados equivalentes, dependendo do cenário de avaliação. No entanto, as comparações realizadas com dois entre os três cenários indicou que grande parte dos casos não concorda no nível de desempenho. O consumo com aquecimento do RTQ-R e o inverno da NBR 15575-1 sempre apresentaram as maiores discordâncias.

Outros exemplos de discordância podem ser citados, como casos que resultaram em nível $\mathrm{E}$ para o RTQ-R nos graus-hora de resfriamento, e nível Intermediário para a NBR 15575-1 no verão. Da mesma forma, há casos que atingiram nível $\mathrm{B}$ pelo RTQ-R no consumo com aquecimento, mas não atendem à NBR 15575-1 no inverno.

A falta de cargas internas, a simplificação da ventilação natural e o fato de usar um programa de simulação dinâmica (EnergyPlus) para realizar simulações de dias típicos podem ser as causas da discordância dos métodos em alguns casos. Entretanto, a análise de sensibilidade mostrou que há pouca diferença nos parâmetros mais influentes entre os métodos, o que remete à própria forma de classificação em níveis considerada.

Uma das inconsistências prováveis seriam as próprias tabelas de classificação dos métodos. Se a tabela de classificação do RTQ-R variasse conforme os limites encontrados na Figura 5 e se a tabela de classificação da NBR 15575-1 variasse conforme os limites encontrados na Figura 6, os métodos poderiam concordar mais. Percebeu-se que a tabela de classificação da NBR 15575-1 é exigente para o inverno, mas pouco exigente no verão. Já para o RTQ-R, a tabela de classificação é muito exigente para os graus-hora de resfriamento e pouco exigente para o consumo com aquecimento (período de inverno), no caso do clima de Florianópolis, SC.

Mais estudos podem ser realizados considerando outras tipologias e climas do Brasil para verificar se os métodos realmente diferem. Da mesma forma, há a necessidade de se estudarem as configurações subjetivas da NBR 15575-1 referentes ao dia típico de projeto, como a radiação solar direta, os dias do ano considerados para o inverno e o verão, e o tipo de céu.

\section{Referências}

ALVES, A. F. M.; PEDRINI, A.; LIMA, G. L. F. Eficiência Energética de Edificações na Zona Bioclimática 08: diretrizes de projeto a partir do método prescritivo do RTQ-R. In: ENCONTRO NACIONAL DE TECNOLOGIA DO AMBIENTE CONSTRUÍDO, 14., Juiz de Fora, 2012. Anais... Juiz de Fora, 2012.

AMERICAN SOCIETY OF HEATING, REFRIGERATING AND AR-CONDITIONING ENGINEERS. Handbook of Fundamentals. Atlanta: ASHRAE, 2005.

\section{AMERICAN SOCIETY OF HEATING, REFRIGERATING AND AR-CONDITIONING ENGINEERS. Standard 90.1: energy standard for buildings except low-rise residential buildings. Atlanta, 2010.}

ASSOCIAÇÃO BRASILEIRA DE NORMAS TÉCNICAS. NBR 15220-3: desempenho térmico de edificações: parte 3: zoneamento bioclimático brasileiro e diretrizes construtivas para habitações unifamiliares de interesse social. Rio de Janeiro, 2005.

\section{ASSOCIAÇÃO BRASILEIRA DE NORMAS TÉCNICAS. NBR 15575-1: edificações habitacionais: desempenho: parte 1: requisitos gerais. Rio de Janeiro, 2013.}

AUGENBROE, G. Trends in Building Simulation. Building and Environment, v. 37, n. 8/9, p. 891902, 2002.

BRASIL. Lei n. 10295, de 17 de outubro de 2001, dispõe sobre a Política Nacional de Conservação e Uso Racional de Energia. Diário Oficial da União, Brasília, 18 de outubro de 2001a. 
BRASIL. Decreto n. 4.059, de 19 de dezembro de 2001, que regulamenta a Lei n⿳⺈ 10.295 , de 17 de outubro de 2001, que dispõe sobre a Política Nacional de Conservação e Uso Racional de Energia, e dá outras providências. Diário Oficial da União, Brasília, 20 de dezembro, 2001b.

BRITO, A. C. et al. Sugestões para Revisão da Norma ABNT NBR 15575:2008, Referentes ao Desempenho Térmico. In: ENCONTRO NACIONAL DE TECNOLOGIA DO AMBIENTE CONSTRUÍDO, 3., Canela, 2010. Anais... Canela: ANTAC, 2010.

CARLO, J. C.; LAMBERTS, R. Parâmetros e Métodos Adotados no Regulamento de Etiquetagem da Eficiência Energética de Edifícios: parte 1: método prescritivo. Ambiente Construído, Porto Alegre, v. 10, n. 2, p. 7-26, abr./jun. 2010.

EMPRESA DE PESQUISA ENERGÉTICA. Balanço Energético Nacional 2012: ano-base 2011. Rio de Janeiro: EPE, 2012. Relatório Final.

\section{ENERGYPLUS. Auxiliary EnergyPlus}

Programs: extra programs for EnergyPlus, 2012.

FERREIRA, C. C.; PEREIRA, I. M. Avaliação do Desempenho Térmico de Habitação de Interesse Social de Acordo com a NBR 15575, para as Diversas Zonas Bioclimáticas. In: ENCONTRO NACIONAL DE TECNOLOGIA DO AMBIENTE CONTRUÍDO. 14., Juiz de Fora, 2012. Anais... Juiz de Fora, 2012.

GU, L. Airflow Network Modeling in EnergyPlus. In: INTERNATIONAL BUILDING PERFORMANCE SIMULATION ASSOCIATION CONFERENCE AND EXHIBITION, 10., Beijing, 2007. Proceedings... Beijing, 2007.

HEO, Y.; CHOUDHARY, R.; AUGENBROE, G. A. Calibration of Building Energy Models For Retrofit Analysis Under Uncertainty. Energy and Buildings, v. 47, n. 4, p. 550-560, 2012.

HOPFE, C. J.; HENSEN, J. L. M. Uncertainty Analysis in Building Performance Simulation for Design Support. Energy and Buildings, v. 43, n. 10, p. 2798-2805, 2011.

INSTITUTO NACIONAL DE METROLOGIA E QUALIDADE INDUSTRIAL. Regulamento

Técnico da Qualidade para o Nível de Eficiência Energética de Edificações Residenciais (RTQR). Rio de Janeiro: INMETRO, 2012. Portaria n. 18.

KELLY, S. Do Homes that Are More Energy Efficient Consume Less Energy? A structural equation model of the English residential sector. Energy, v. 36, n. 9, p. 5610-5620, 2011.
LIMA, G.; PEDRINI, A.; ALVES, A. Avaliação do Desempenho Térmico de Uma Habitação de Interesse Social Localizada no Clima Quente e Úmido da Cidade de Parnamirim/RN Com Base no Método de Simulação do RTQ-R. In: ENCONTRO NACIONAL DE TECNOLOGIA DO AMBIENTE CONSTRUÍDO, 14., Juiz de Fora, 2012. Anais... Juiz de Fora, 2012.

LOURA, R. M.; ASSIS, E. S. de; BASTOS, L. E. G. Análise Comparativa entre Resultados de Desempenho Térmico de Envoltórias de Edifícios Residenciais Gerados por Diferentes Normas Brasileiras. In: ENCONTRO NACIONAL CONFORTO NO AMBIENTE CONTRUÍDO, 7.; ENCONTRO LATINO AMERICANO DE CONFORTO NO AMBIENTE CONTRUÍDO, 11., Búzios, 2011. Anais... Búzios, 2011.

MACDONALD, I.; STRACHAN, P. Practical Application of Uncertainty Analysis. Energy and Buildings, v. 33, n. 3, p. 219-227, 2001.

MARIN, P.; AMORIM, C. N. D. Estratégias Para a Eficiência Energética de Residências Unifamiliares na Serra Gaúcha: uma análise baseada no RTQ-R. In: ENCONTRO NATIONAL DE TECNOLOGIA DO AMBIENTE CONSTRUÍDO, 14., Juiz de Fora, 2012. Anais... Juiz de Fora, 2012.

MELO, A. P. Desenvolvimento de um Método para Estimar o Consumo de Energia de Edificações Comerciais Através da Aplicação de Redes Neurais. Florianópolis, 2012. Tese (Doutorado em Engenharia Civil). Universidade Federal de Santa Catarina, Floranópolis, 2012.

NOGUEIRA, F. H. S. et al. Análise da Envoltória pelo Método Prescritivo do RTQ-R: etiquetagem de residência unifamiliar em Maceió-AL. In: ENCONTRO NACIONAL DE TECNOLOGIA DO AMBIENTE CONSTRUÍDO, 14., Juiz de Fora, 2012. Anais... Juiz de Fora, 2012.

POUEY, J. A. A.; BRANDALISE, M. P.; SILVA, A. C. S. B. Determinação da Eficiência Energética da Envoltória de Projeto Residencial Unifamiliar Comparando os Resultados a Partir da Aplicação dos Métodos Prescritivo e de Simulação do RTQR. In: ENCONTRO NACIONAL DE TECNOLOGIA DO AMBIENTE CONSTRUÍDO, 14., Juiz de Fora, 2012. Anais... Juiz de Fora, out. 2012.

RAFTERY, P.; KEANE, M.; O'DONNELL, J. Calibrating Whole Building Energy Models: an evidence-based methodology. Energy and Buildings, v. 43, n. 9, p. 2356-2364, 2011. 
SIGNOR, R. Análise de Regressão do Consumo de Energia Elétrica Frente a Variáveis Arquitetônicas para Edifícios Comerciais Climatizados em 14 Capitais Brasileiras.

Florianópolis, 1999. Dissertação (Mestrado em Engenharia Civil) - Universidade Federal de Santa Catarina, Florianópolis, 1999.
SILVA, V. G. Indicadores de Sustentabilidade de Edifícios: estado da arte e desafios para desenvolvimento no Brasil. Ambiente Construído, Porto Alegre, v. 7, n. 1, p. 47-66, jan./mar. 2007.

\section{Agradecimentos}

Os autores agradecem à Finep e ao $\mathrm{CNPq}$, pelo financiamento do projeto que originou esta pesquisa.

\section{Arthur Santos Silva}

Laboratório de Eficiência Energética em Edificações, Departamento de Engenharia Civil | Universidade Federal de Santa Catarina | Caixa Postal 476 | Florianópolis - SC - Brasil | CEP 88040-900 | Tel.: (48) 3721-5184 | E-mail: arthurssilva07@gmail.com

\section{Enedir Ghisi}

Laboratório de Eficiência Energética em Edificações, Departamento de Engenharia Civil | Universidade Federal de Santa Catarina | E-mail: enedir@labeee.ufsc.br

\section{Revista Ambiente Construído}

Associação Nacional de Tecnologia do Ambiente Construído

Av. Osvaldo Aranha, $99-3^{\circ}$ andar, Centro

Porto Alegre - RS - Brasil

CEP $90035-190$

Telefone: +55 (51) 3308-4084

Fax: +55 (51) 3308-4054

www.seer.ufrgs.br/ambienteconstruido

E-mail: ambienteconstruido@ufrgs.br 